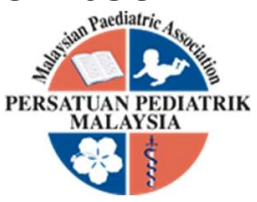

\title{
CONTINUOUS GLUCOSE MONITORING SYSTEM VERSUS SELF- MONITORING BLOOD GLUCOSE IN TYPE 1 DIABETES MELLITUS CHILDREN: A RANDOMISED CONTROLLED TRIAL (ROSEC)
}

\author{
Muhd Alwi Muhd Helmi' , Norsa'adah Bachok ${ }^{2}$, Suhaimi Hussain ${ }^{3}$
}

\begin{abstract}
Objectives: The primary and secondary objectives were to compare the glycaemic control and frequency of hypoglycaemia between continuous glucose monitoring system (CGMS) and self-monitoring blood glucose (SMBG). Methods: A single centre, randomised, parallel-group controlled trial was conducted involving twenty-two type one Diabetes Mellitus (T1DM) patients with the mean age of 13.8 years assigned to either intervention or control group. All respondents wore the CGMS device at the beginning of the study. Intervention group ( $n=11$ ) had their insulin adjusted based on the CGMS data, while the control group ( $n=11$ ) was based on SMBG. Monthly average blood sugar level (BSL) and monthly mean hypoglycemic events per week (HE/wk) were measured at baseline, first month, second month, and third month. HbA1c levels were measured at baseline and in the third month. Results: The baseline characteristics were similar. The data were analysed using repeated measure analysis of variance (ANOVA). The mean difference of $\mathrm{HbA} 1 \mathrm{c}$ within the group was not statistically significant with $p=0.322$. There were significant differences in the monthly mean $\mathrm{HE} / \mathrm{wk}$ within and between groups, $\mathrm{p}=0.004$, and $p=0.037$. Conclusion: In conclusion, CGMS is equivalent to SMBG in optimising glycaemic control but is more effective in detecting hypoglycaemia in children.
\end{abstract}

Keywords: Continuous Glucose Monitoring System, Self-monitoring Blood Glucose, Type 1 Diabetes

DOI: $10.51407 / \mathrm{mjpch} . v 27 \mathrm{i} 2.152$

\section{Introduction}

The incidence of Type 1 Diabetes Mellitus (T1DM) is increasing by $3 \%$ annually worldwide $[1,2]$. T1DM is the most common form of Diabetes Mellitus (DM) and accounts for $74.4 \%$ of all diabetic children and adolescents in Malaysia. T1DM is associated with various neurological and cardiovascular complications [1,3]. It has a seven times higher risk of death from coronary heart disease compared to the normal population and two times more than in Type 2 Diabetes Mellitus [4]. A good glycaemic control reduced the risk of neuropathy and a more than $50 \%$ reduction in the early stages of microvascular complications such as retinopathy and nephropathy in patients with T1DM [5]. Few factors could affect glycaemic
Received: 17 March 2021; Accepted revised manuscript: 25 July 2021

Published online: 25 November 2021 control among children and adolescents with T1DM. These include age [6], BMI, high daily basal insulin dose [1,7], duration of diabetes [8-10], compliance to blood glucose monitoring and insulin regimen [11-13], types of insulin, and quality of life $[14,15]$.

\footnotetext{
'Paediatric Department, Kulliyyah of Medicine, International Islamic University Malaysia, Kuantan 25200, Pahang, Malaysia. ${ }^{2}$ Unit of Biostatistics \& Research Methodology, School of Medical Sciences, Universiti Sains Malaysia, Kubang Kerian, 16130, Kelantan, Malaysia

${ }^{3}$ Paediatric Department, School of Medical Sciences, Universiti Sains Malaysia, School of Medical Sciences, Kubang Kerian, 16130, Kelantan, Malaysia. Corresponding Author:

Suhaimi Hussain, Paediatric Department, School of Medical Sciences, Universiti Sains Malaysia, School of Medical Sciences, Kubang Kerian, 16130, Kelantan, Malaysia Tel.: 6097676947 Email: hsuhaimi@usm.my
} 
In Malaysia, more than $50 \%$ of T1DM patients age less than twenty years old have poor glycaemic control with $\mathrm{HbA} 1 \mathrm{c}$ of more than $10.0 \%$ [1]. Good metabolic control can be achieved with intensive therapy and more frequent monitoring of blood glucose $[4,9,14]$. Self-monitoring blood glucose (SMBG) has been the conventional means of blood glucose monitoring at home. However, SMBG only provides intermittent readings of glucose level without giving a whole 24-hourpicture of glucose variability. Alternatively, the Continuous Glucose Monitoring System (CGMS) was introduced in the early year 2000. CGMS measures subcutaneous interstitial fluid glucose every few minutes for a few days [16]. It offers the potential to optimise glycaemic control as well as to detect subclinical hypoglycaemic events. CGMS device can be integrated with an insulin pump to analyse and fine-tune insulin dose in either real-time or retrospective more accurately [17].

\section{This RoSEC (Research on Safety and Effectiveness}

of Continuous Glucose Monitoring System) trial aims to determine whether the use of data from retrospective CGMS to fine-tune insulin dosage would result in better $\mathrm{HbA} 1 \mathrm{c}$ and average BSL per month without increasing the frequency of hypoglycemia as compared to the conventional Self-monitoring blood glucose (SMBG) method.

\section{Methods}

This RoSEC study was a single centre, randomised, and parallel-group controlled trial with equal randomisation (allocation ratio 1:1) conducted at Paediatric Endocrinology Clinic, Hospital Universiti Sains Malaysia (USM). Hospital USM is a tertiary teaching hospital and is the only centre with paediatric endocrinology service for the whole east coast of Malaysia peninsular. Respondents were randomly assigned to one of the two groups, the control and intervention group. The intervention group had their insulin dosage adjusted based on CGMS data, while the control group had their insulin dosage adjusted based on SMBG recording. Figure 1 shows the respondent flow diagram.

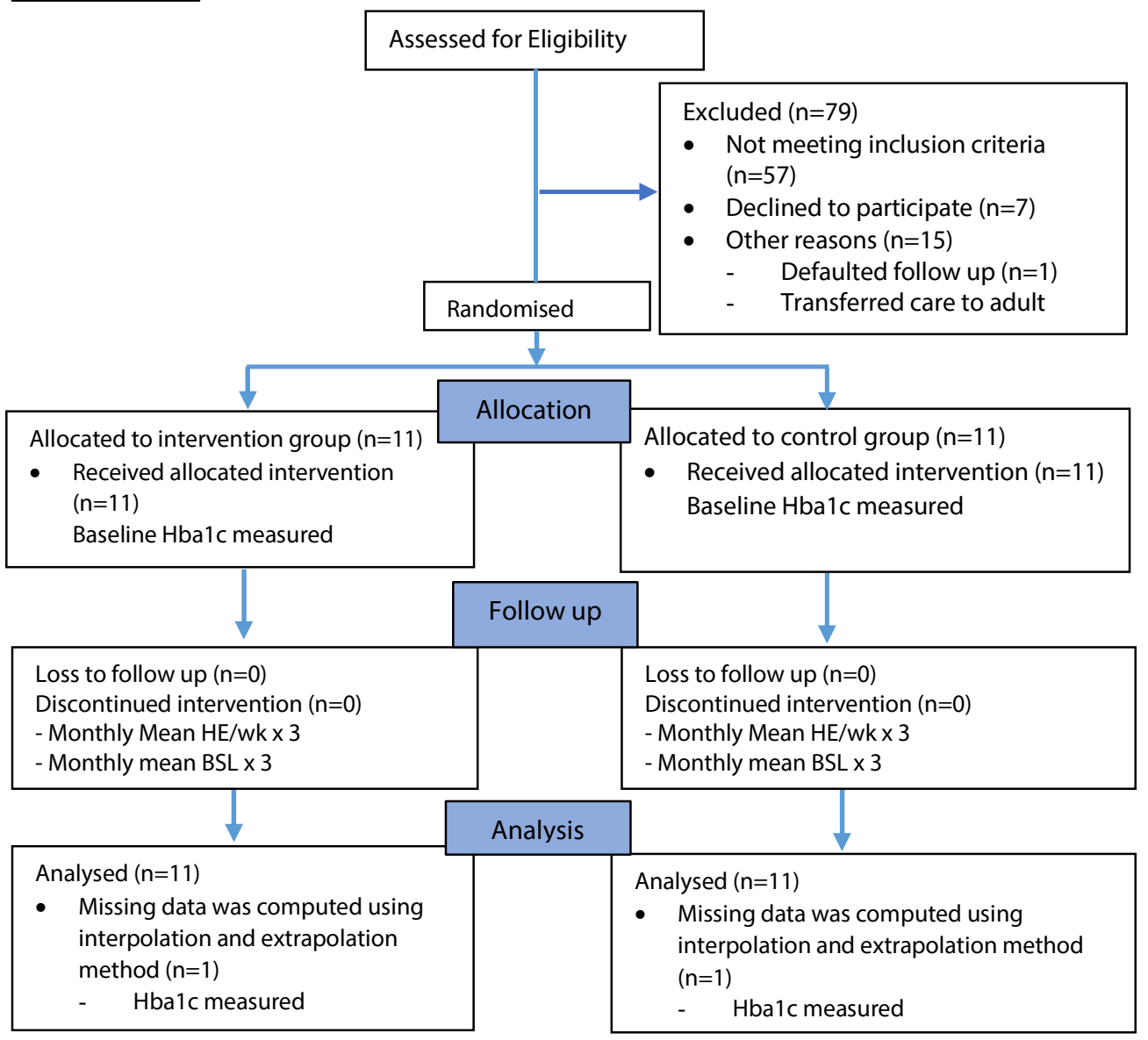

Figure 1. Respondent Flow Diagram

All respondents enrolled were analysed for all the outcome $(n=22)$. One respondent in each group has incomplete data. Both respondent loss their log books during the follow up. The lost data were imputed using interpolation and extrapolation method by estimating the missing value from other observations from the same respondent. 


\section{Selection and description of participants}

All children attending Hospital USM paediatric diabetic clinic follow up are eligible for this study. Included in this study were any children age more than seven years old with poorly controlled T1DM defined as a patient with baseline $\mathrm{HbA} 1 \mathrm{c}$ of more than $7.0 \%$ or had more than $10 \%$ hypoglycaemic episodes per week with the onset of diabetes of more than twelve months. All respondents must be on intensive insulin regimens, which are three or more daily insulin injections. Other types of Diabetes Mellitus and children diagnosed with any genetic syndrome were excluded from this trial.

Baseline characteristics of the respondents were determined before the intervention. The anthropometric data were measured and plotted on the appropriate CDC growth chart for age and sex to determine the respective weight and height percentile. Weight and height percentile of less than fifth percentile were classified as short and underweight while between 5th and 85th percentile as normal weight and height. Weight above 85th percentile was considered overweight and obese [18]. Respondents' baseline economic status was grouped into B40, M40, or T20, depending on the total monthly household income. B40, M40, and T20 have household income levels below USD 1060, between USD 1060 and USD 2340 and $\geq$ USD 2340, respectively [19].

\section{Technical information}

\section{Randomisation}

\subsection{Sequence Generation}

The random sequence was generated using online software by a dedicated research assistant [20]. Two random sequences of numbers were generated to allocate each respondent to either the control or intervention group.

1.2. Allocation concealment mechanism and implementation

All respondents used the CGMS device at the beginning of the study as a blinding method to conceal the group allocation. They also underwent the same procedures and were blinded from the CGMS data. A dedicated research assistant who was not involved in data collection and analysis did the group allocation procedure. Respondents chose a sealed opaque envelope containing random numbers that are part of the allocation sequence during a prestudy clinic visit. The enclosed number was placed in between two pieces of opaque black papers in the envelope. This method prevented the light from passing through the envelope and hence concealed the number. The chosen envelope was kept in a dedicated drawer with respondents' hospital ID number written on it. The research assistant then opened the envelope to identify the chosen number and the group allocation in different settings and time in the absence of the respondents. The allocation was made known only to the clinicians involved in the study. Respondents were not informed about the number and group allocation.

\subsection{Type of randomisation}

Since the insulin delivery method, i.e., pump vs self-injection, will affect glycaemic control, respondents were stratified to either pump or self-injection [9]. The subgroups were then assigned to either the control or intervention group using simple randomisation based on a computer-generated sequence. The group allocation depends on the random number available inside the opaque envelopes.

\subsection{Blinding}

This study's design made it impossible to blind the clinician who reviewed the CGMS and SMBG data. Some parties involved in this research were blinded throughout the study period. Respondents and their family members were blinded to the group allocation and the CGMS data. Research assistants who helped in downloading the CGMS data were blinded to the randomisation. Respondents identities were kept anonymous, and they were identified only by the allocation number. Clinic nurses were not informed about the group allocation. The CGMS and SMBG data were blinded from them. Other clinicians besides the interventionist and data collectors were blinded from the CGMS data and the outcomes. The lab technician who ran the HbA1c test was blinded from the respondents' participation in the study. All respondents underwent the same procedures and investigations. Therefore, all respondents were given the same instruction and briefing at the beginning of the study. 


\section{Sample size}

Changes in glycaemic control (HbA1c) withingroup pre and post-intervention is the primary outcome of RoSEC study. With 11 respondents per group, we can reject the null hypothesis that the mean within groups pre and postintervention are equal if the $p$-value $<0.05$ has the power of study 0.80 . In a previous study, the within-group mean difference of HbA1c has a standard deviation of 1.1 [21]. The mean difference to be detected based on the expert view is $1.0 \%$. There was no dropout in this study. Recruitment into this trial ended after 22 respondents were recruited.

\section{Interventions}

At the beginning of the study, all respondents used CGMS (Medtronic iPro2 Professional CGM device with enlite sensor) for one week on top of their usual pre-prandial and pre-bed self-glucose monitoring at least four times per day (prebreakfast, pre-lunch, pre-dinner, pre-bed). After one week, the device was removed, and the data was downloaded. The CGMS data from the respondents in the intervention group was used to adjust the insulin dose to be injected by the respondents for the next 12 weeks, while the CGMS data from the control group was stored and not analysed. The insulin dose was adjusted based solely on the respondent's glucose monitoring in the control group. Throughout the 12-week period, respondents continued their usual pre-prandial capillary blood glucose monitoring at least four times per day.

\section{Similarities of intervention}

Every respondent in each group used the CGMS device at the beginning of the study for one week and at least four times per day capillary blood sugar monitoring. The same device was used and placed at the same site of the body, i.e. the abdomen. Post CGMS, all respondents continued their regular SMBG and routine three months follow up. All respondents received the same level of care and received a phone call and text messages reminder to comply with regular SMBG monitoring and insulin dosage as prescribed by the clinician.

\section{Outcomes}

The primary outcome of the study is $\mathrm{HbA} 1 \mathrm{c}$ level. Hba1c was measured using the technique of affinity chromatography done locally at HUSM endocrine laboratory. The results were presented using the National Glycohemoglobin
Standardization program (NGCP) standard [22]. The test was conducted by lab technicians specialised in endocrine investigations. The lab technicians were blinded from the respondents' participation in the study. $\mathrm{HbA} 1 \mathrm{c}$ was measured two times, at the beginning of the study period (baseline) and the end of week-12. The mean $\mathrm{HbA} 1 \mathrm{c}$ value pre and post-intervention at 12 weeks within the group were compared. This comparison is to determine the effectiveness of both CGMS and SMBG. A comparison of mean $\mathrm{HbA} 1 \mathrm{c}$ between the groups post-intervention determined the significance of CGMS compared to SMBG in improving glycaemic control.

Secondary outcomes are mean hypoglycaemic events per week (HE/wk) and monthly mean blood sugar level (BSL) at months 1, 2, and 3 post insulin adjustment. Hypoglycaemia is defined as a capillary sugar level of less than $3.9 \mathrm{mmol} / \mathrm{L}$, as recorded by the respondents using SMBG. Mean BSL per month is defined as the average BSL for the whole month as recorded by respondents using SMBG. The monthly mean $\mathrm{HE} / \mathrm{wk}$ was calculated by dividing the total number of hypoglycaemia detected using SMBG in the first 28 days of the month by 4 . All BSL were measured using a standardised glucometer and glucose strips provided to all the respondents at the beginning of the study. The secondary outcomes were assessed at the end of the third month by reviewing all the recorded BSL in the respondents' logbooks. The assessment of all the secondary outcomes were done by a dedicated research assistant blinded to the respondents' group allocation. There are no changes to the trial outcomes upon commencement of the trial.

\section{Ethical Issues}

This trial was conducted in concordance with the Declaration of Helsinki and complied with the Malaysian Good Clinical Practice (GCP) guidelines (all investigators are GCP certified researchers). Ethical clearance was obtained from the Human Research Ethics Committee USM before commencement (study protocol code: USM/JEPeM 17080378). Personal information was safeguarded to ensure confidentiality. The risk to the safety or health of the respondents was minimal. All measures had been taken to reduce harm to the patients, including the use of analgesic cream. Since most respondents were vulnerable (below 18 years old), consent and assent were obtained according to the ethical 
committee requirements. (Under seven years old: parental consent only, 7 to under 12 years old: verbal assent, 12 to under 15 years old: assent form, 15 to under 18 years old: co-sign informed consent form with parents). Respondents were given the right to withdraw from the study at any point as the study recruitment is voluntary. All forms were anonymous using coded numbers when entered into SPSS software. Only research team members have access to the data. Data are presented as grouped data and do not identify the respondent individually. A separate list of names and registration number with coded number was kept by the researcher in a locked cabinet.

\section{Statistics}

Data were analysed using SPSS version 24. The demographic and numerical data are presented by mean and SD or median and interquartile range (IQR) according to data distribution. The categorical data are expressed as number and percentage. Since all outcomes are numerical, repeated measure analysis of variance (ANOVA) was used to determine the significance of the difference between mean $\mathrm{HbA} 1 \mathrm{c}$, mean $\mathrm{HE} / \mathrm{wk}$, and monthly mean BSL between groups, the time effect, and interaction between time and intervention group.

\section{Results}

One hundred and one diabetic patients were screened for eligibility. Twenty-two respondents were recruited from July 2018 until January 2019. All respondents were followed up for 12 weeks after one week of CGMS application. Regular phone calls and text messages were made to ensure compliance with the study protocol and monitor for complications such as hypoglycaemia. The trial ended after all 22 respondents completed the three-month followup.

\section{Baseline characteristics}

The baseline $\mathrm{HbA} 1 \mathrm{c}$ was taken within three months before the use of CGMS device. Summary of baseline and demographic characteristics of respondents are presented in Table 1. Our cohort, in general, had poor glycaemic control at baseline with a mean $\mathrm{HbA} 1 \mathrm{c}$ of $10.8 \%$. The baseline $\mathrm{HbA} 1 \mathrm{c}$ was similar between both groups with $p$ value 0.564 . Three out of the twenty-two respondents (14\%) had optimal HbA1c $(<7.5 \%)$, four (18\%) with sub-optimal control, while the rest $68 \%$ falls within poor control diabetes (HbA1c>9.0\%) based on Malaysia Clinical Practice Guideline 2015 [23]. This percentage is better compared to $6 \%$ of all T1DM from the national registry [1]. However, the glycaemic control among patients was variable with $\mathrm{HbA} 1 \mathrm{c}$ ranges between $6.8 \%$ to $15.8 \%$. Respondents in both groups had similar baseline characteristics except for baseline frequency of HE/wk, $p$ value 0.039 . Two respondents in the intervention group and one respondent in the control group were on an insulin pump while the rest were on basal-bolus insulin. 
Table 1. Baseline and demographic characteristics of respondents

\begin{tabular}{|c|c|c|c|}
\hline \multirow[b]{2}{*}{ Characteristic } & \multicolumn{2}{|c|}{ Frequency (\%) } & \multirow[b]{2}{*}{ P value } \\
\hline & $\begin{array}{l}\text { Intervention } \\
(n=11)\end{array}$ & Control $(n=11)$ & \\
\hline Age (years) & $12.73(2.37)^{a}$ & $14.91(3.67)$ & $0.114^{\gamma}$ \\
\hline \multicolumn{4}{|l|}{ Gender: } \\
\hline Male & $7(70.0)$ & $3(30.0)$ & $0.087^{\varepsilon}$ \\
\hline Female & $4(33.3)$ & $8(66.7)$ & \\
\hline \multicolumn{4}{|l|}{ Race: } \\
\hline Malay & $9(45.0)$ & $11(55.0)$ & $0.476^{\zeta}$ \\
\hline Chinese & $2(100.0)$ & $0(0.0)$ & \\
\hline BMI $\left(\mathbf{k g} / \mathbf{m}^{2}\right)$ & $18.47(5.16)^{a}$ & $18.27(3.51)$ & $0.916^{\gamma}$ \\
\hline \multicolumn{4}{|l|}{ Type of insulin } \\
\hline Human & $1(50)$ & $1(50)$ & $0.202^{\varepsilon}$ \\
\hline Analogue & $3(30)$ & $7(70)$ & \\
\hline Combined Human and Analogue & $7(70)$ & $3(30)$ & \\
\hline Duration of DM (months) & $48(48)^{\beta}$ & $48(76)$ & $0.949^{\delta}$ \\
\hline \multicolumn{4}{|l|}{ Insulin Delivery } \\
\hline Injection & $9(47.4)$ & $10(52.6)$ & $1.00^{\zeta}$ \\
\hline Pump & $2(66.7)$ & $1(33.3)$ & \\
\hline Total daily insulin dose (IU/kg/day) & $1.07(0.48)^{\beta}$ & $1.28(0.69)$ & $0.264^{\delta}$ \\
\hline Daily basal insulin (IU/kg/day) & $0.45(0.21)^{\beta}$ & $0.48(0.15)$ & $0.350^{\delta}$ \\
\hline \multicolumn{4}{|l|}{ Economic status ${ }^{\ddagger}$} \\
\hline B40 & $5(35.7)$ & $9(64.3)$ & $0.875^{\varepsilon}$ \\
\hline M40 & $4(66.7)$ & $2(33.3)$ & \\
\hline $\mathrm{T} 20$ & $2(100)$ & $0(0)$ & \\
\hline \multicolumn{4}{|l|}{ Monthly BSL } \\
\hline Lowest & $3.4(2)^{\beta}$ & $3.6(1)$ & $0.277^{\delta}$ \\
\hline Highest & $17.1(5.04)$ & $14.0(4.06)$ & 0.564 \\
\hline Average & $8.2(2.78)$ & $7.78(4.31)$ & 0.450 \\
\hline Hypoglycemic events per week (HE/wk) & $3(4)^{\beta}$ & $1(2)$ & $0.039^{\delta}$ \\
\hline Baseline HbA1c (\%) & $10.6(2.68)^{a}$ & $10.9(3.03)$ & 0.564 \\
\hline
\end{tabular}

${ }^{a}$ Mean(sd), ${ }^{\beta}$ Median(IQR)

${ }^{\gamma}$ Independent t-test, ${ }^{\delta}$ Mann-Whitney, ${ }^{\varepsilon}$ Chi-square test, ${ }^{\zeta}$ Fisher-exact test

FB40, M40 and T20 are those with household income levels of less than USD 1060, between USD 1060 and USD 2340 and $\geq$ USD 2340 respectively 
2. Numbers analysed

The data were analysed with the intention-totreat, and all respondents enrolled at the beginning of the study were analysed. All respondents were analysed for all the outcomes $(n=22)$. Two respondents, one in each group, had missing data. The two respondents lost their logbooks, and the daily BSL recording for the third month cannot be retrieved. Missing data were imputed using the interpolation and extrapolation method by imputing the missing values from other earlier observations and other available data from the same respondent. Interpolation and extrapolation method is used because all the outcomes were related to each other in this study. For instance, an increase in $\mathrm{HbA} 1 \mathrm{c}$ reflects the increase in the mean BSL and the reduction in hypoglycaemic events. All respondents completed one week of CGMS usage. Three patients had incomplete recordings due to faulty CGMS devices. However, all three respondents have at least $40 \%$ of the recordings completed.

\section{Outcome and estimation}

\subsection{Glycaemic control}

The mean $\mathrm{HbA} 1 \mathrm{c}$ in both groups increased from baseline after 12 weeks. Compared to the control group, the increment in mean $\mathrm{HbA} 1 \mathrm{c}$ in the intervention group was lesser. Figure 2 shows the changes in $\mathrm{HbA} 1 \mathrm{c}$ over time in the intervention and control groups. There was no significant difference for mean $\mathrm{HbA} 1 \mathrm{c}$ with time for both the control and intervention group; $F(1,20)=1.032$, $p=0.322$. The mean difference between the two groups was not significant; $F(1,20)=0.118$, $\mathrm{p}=0.735$ and there was no interaction found between $\mathrm{HbA} 1 \mathrm{C}$ and the group; $\mathrm{F}(1,20)=0.136$ $p=0.716$. The average BSL per month fluctuated across time, as shown in Figure 3. There was no significant mean difference in average BSL per month between the control and intervention groups and within each group. $F(1,20)=0.195$, $p=0.663$ and $F(3,60)=0.854, p=0.400$. There was no interaction between average BSL per month and the group, $F(3,60)=0.589, p=0.625$.

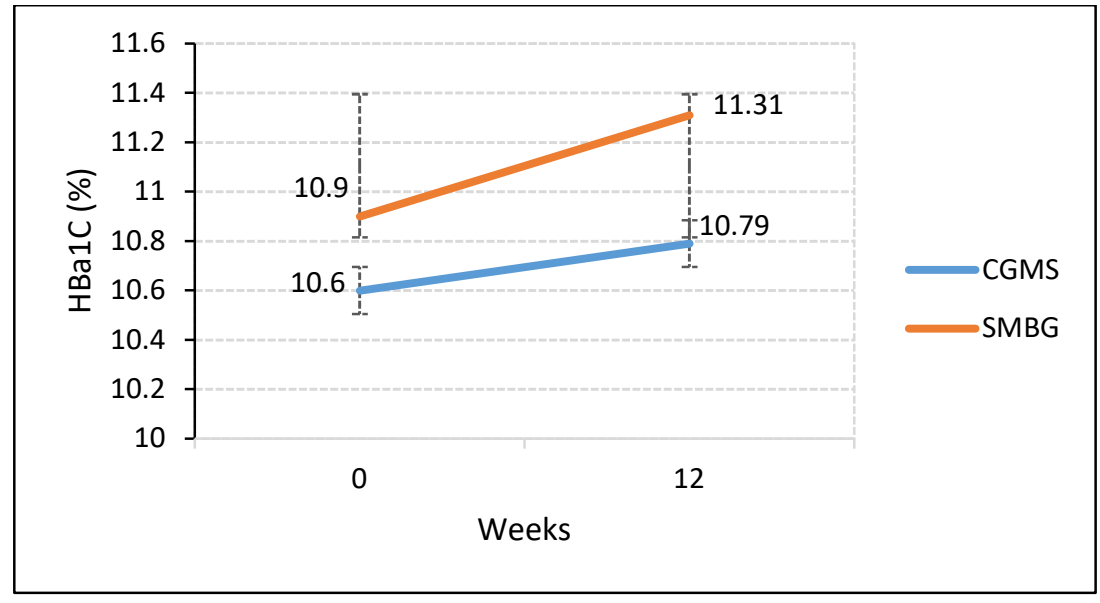

Figure 2. Comparison of changes in the mean $\mathrm{HbA1c}$ pre (week 0) and post-intervention (week 12) between CGMS and SMBG groups. 


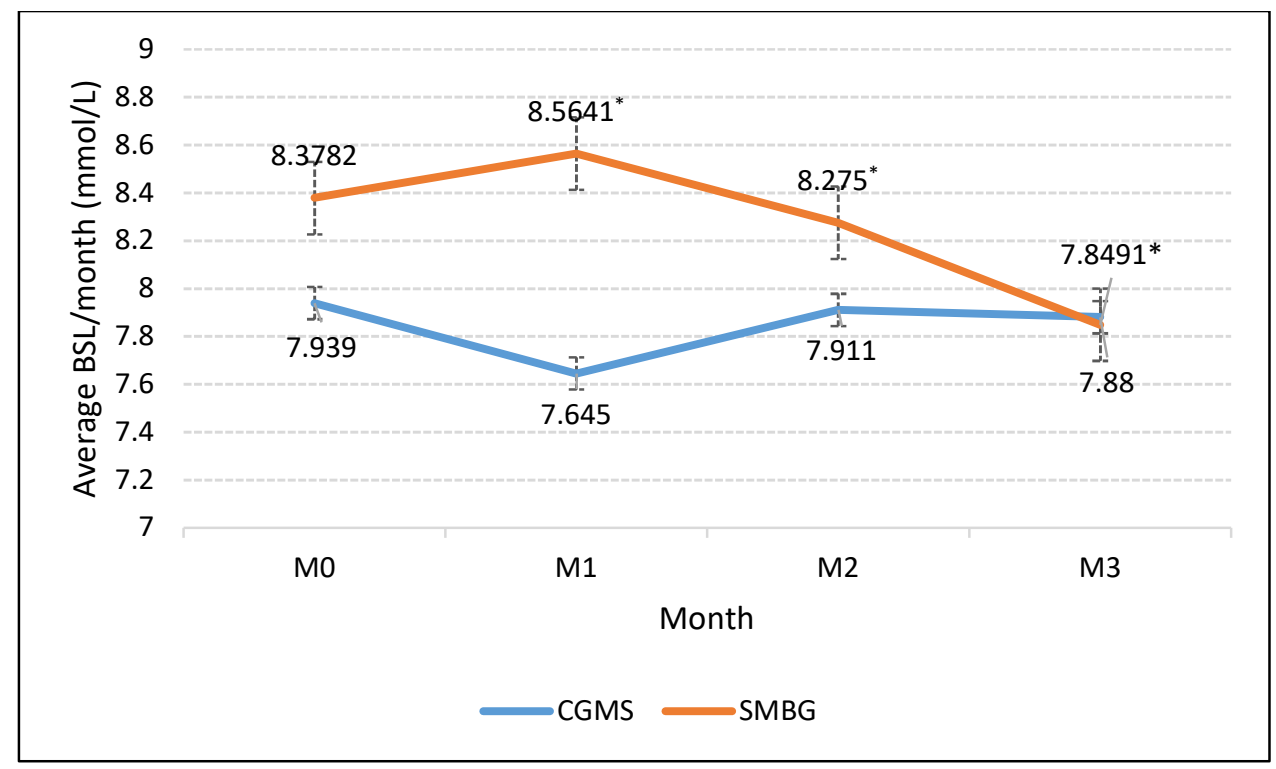

Figure 3. Comparison of average BSL per month in the intervention and control groups at $0,1,2$ and 3 months.

*significant difference seen within group with time M1-M2 and M2-M3 with $\mathrm{p}$-value 0.002 and 0.022 respectively.

\subsection{Hypoglycaemia}

The mean monthly hypoglycaemic events (HE/wk) in control and intervention groups decreased with a statistically significant difference after insulin adjustment.. The reduction was greater in the intervention group $F(1,20)$ $=4.982, \mathrm{p}=0.037$. The mean difference between $\mathrm{HE} /$ wk with time also showed a statistically significant difference $F(3,60)=9.752, p=0.004$.
There was no interaction between hypoglycaemia and group $F(3,60)=2.533, p=0.124$. Figure 4 shows the HE/wk in both groups at baseline, first, second and third month. Only one respondent in the SMBG group had severe hypoglycaemic events requiring assistance. This episode occurred while the respondent was on CGMS. No mild hypoglycaemia episodes reported by other respondents.

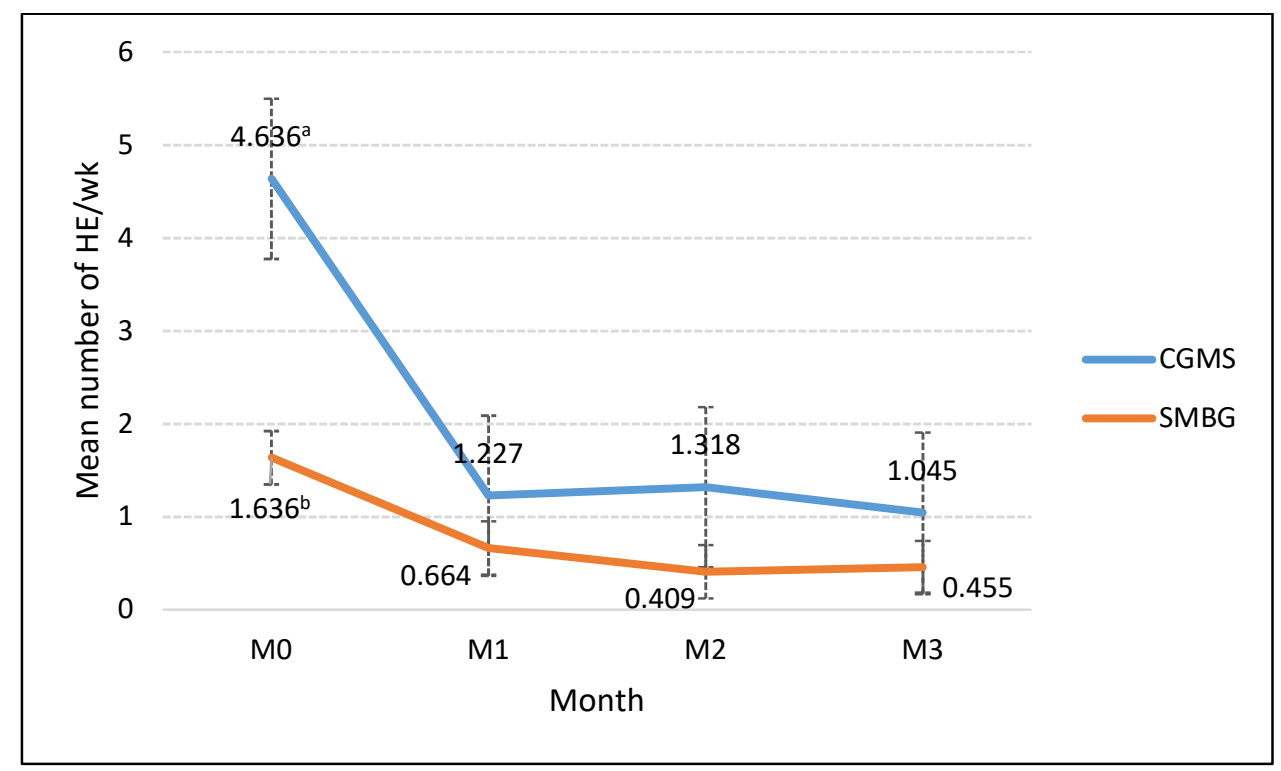

Figure 4. Comparison of mean number of hypoglycaemic events per week (HE/wk) between CGMS and SMBG at $0,1,2$ and 3 months.

There are significant differences for mean hypoglycaemic events per week with time for both CGMS and SMBG group. 


\section{Harms}

Pain induced by CGMS device was minimal. None of the respondents complained of pain at the insertion site. However, 8 out of 22 (36.3\%) respondents complained of mild discomfort at the attachment site and restriction of physical activities associated with fear of device dislodgement. Respondents had to be mindful and need extra care when doing their regular daily activity to prevent dislodge for the whole one week of usage.

\section{Discussion}

This study is the first trial in Malaysia and possibly in Southeast Asia, on the use of retrospective CGMS in T1DM children and adolescents. We found that respondents with better control tend to be younger with a shorter duration of diabetes and with lower baseline mean BSL per month, while those with poorer control were adolescents. These findings were similar to a few other studies that looked at demographic factors associated with glycaemic control in Type 1 Diabetes children $[6,7]$. Noorani et al. found that a younger age group of $<10$ years old and shorter illness duration had significantly lower $\mathrm{HbA1c}$ than the older age group [7]. Gesuita et al. demonstrated that every additional year with diabetes reduces the chance of having $\mathrm{HbA} 1 \mathrm{c}$ within target by $11 \%$ [6]. We recruited children with at least one year of diagnosis to avoid the partial remission period. The lower $\mathrm{HbA} 1 \mathrm{c}$ in younger children may be due to close supervision by parents that leads to greater compliance to blood glucose monitoring and insulin therapy [7]. Lower mean BSL gives rise to a lower HbA1c level [24]. Zhou et al., in a study that looks into the relationship between $\mathrm{HbA} 1 \mathrm{c}$ and means daily BSL as recorded by CGMS, found that $\mathrm{HbA} 1 \mathrm{c}$ and mean $\mathrm{BSL}$ were highly correlated with each other [25], and $\mathrm{HbA} 1 \mathrm{c}$ can be estimated with high accuracy using mean BSL [25].

Teenagers and adolescents have poorer glycaemic control compared to younger children $[6,13]$. This finding has been demonstrated in multiple studies on glycaemic control among teenagers with T1DM $[6,7,26]$. In a large-scale longitudinal study involving more than 27000 T1DM children and adolescents from 207 centres in Germany, patients aged between 11 and 20 had significantly higher $\mathrm{HbA} 1 \mathrm{c}$ than other age groups [26]. In the United States Type 1 Diabetes registry 2016-2018, only $21 \%$ of adolescents achieved the American Diabetic Association $\mathrm{HbA} 1 \mathrm{c}$ target, and the percentages were lower than the previous registry in 2010-2012 [27]. Longer duration of diabetes that leads to burnout, hormonal and physical changes such as increasing sex and growth hormones, lesser parental supervision, and other psychosocial and behavioural issues associated with teenagers contribute to the poorer glycaemic control in high risk population $[6,7,13]$.

In the International Society for Pediatric and Adolescent Diabetes (ISPAD) Clinical Practice Consensus Guideline 2018, ISPAD recommended that basal insulin dose be set at between 30 and $45 \%$ of the total daily insulin dose [28]. The percentage can be up to $50 \%$ if the insulin analogue is used [28]. A high basal insulin dose contributed to poorer glycaemic control in patients with T1DM [29]. For instance, Strich, et al. in a retrospective study that looked at the effect of lower basal insulin on HbA1c, found that patients with optimum $\mathrm{HbA1c}$ levels had a significantly lower percerisk ntage of basal insulin than patients with higher HbA1c [29]. Basal insulin of $35 \% \pm 10 \%$ of the total daily insulin dose was associated with the most optimal HbA1c [29]. In another study involving 260 T1DM patients on an insulin pump, Matejko et al. reported that respondents with a percentage basal insulin of less than $30 \%$ had significantly lower $\mathrm{HbA1c}$ [30]. The high basal insulin causes frequent intermittent hypoglycaemia with hyperphagia increasing snacking and carbohydrate intake [31]. Despite our respondents having a high basal insulin dose at around $0.5 \mathrm{u} / \mathrm{kg} / \mathrm{day}$, the mean basal insulin dose was less than $40 \%$ of the mean total daily insulin. Therefore, this is most likely not the contributing factor to the high $\mathrm{HbA} 1 \mathrm{c}$ among our respondents. Adolescents required a higher insulin dose than younger children due to relative insulin insensitivity associated with the effect of growth and sex hormones secretion [3].

The majority $(63.6 \%)$ of our respondents came from a low socioeconomic background, the B40 group. The socioeconomic level can negatively affect $\mathrm{HbA1c}[6,32,33]$. For instance, in an observational study involving 222 T1DM children aged 8 to 17 years old, Hassan and colleagues found that socioeconomic status inversely proportionate to the $\mathrm{HbA} 1 \mathrm{c}$ level [32]. Patients 
with low socioeconomic backgrounds tend to monitor their BSL less frequently and thus have poorer glycaemic control [34]. Carter et al. have demonstrated this relationship in their study where T1DM patients among the poor Maori and Pacific ethnics monitor their daily SMBG significantly less frequently and had significantly higher HbA1c [34]. Socioeconomic status also relates well to parental educational level $[6,32,33]$. Gesuita et al. found that maternal educational level was significantly lower among patients with poor glycaemic control with p-value of 0.027 [6]. Parents with a good education would be able to guide and assist their children on insulin adjustment, calorie counting, and better identify and manage crises such as hyper and hypoglycaemic events [6,33]. The high $\mathrm{HbA1c}$ might also be contributed by factors independent of glycaemic control such as iron deficiency, races, and genetic variation [35-37].

The use of one-week CGMS retrospectively is no more superior to SMBG in improving respondents' glycaemic control, the $\mathrm{HbA1c}$ and the average BSL per month. Our result is comparable to other trials from both developed and developing countries [17,21,38,39]. For instance, Raviteja et al. found that when data from 72 hours of CGMS were used to adjust insulin dosage for the next three months, the reduction in $\mathrm{HbA} 1 \mathrm{c}$ was not significantly different compared to the control group [39]. Deiss et al. reported similar findings. In a crossover study involving 30 T1DM children, the change in mean $\mathrm{HbA} 1 \mathrm{c}$ and other glycaemic parameters were not significantly different between CGMS and SMBG groups [21]. In a meta-analysis of five paediatric randomised control trials of mixed design parallel and crossover that compare retrospective CGMS and SMBG, there was no difference in the effectiveness of both methods in reducing the mean $\mathrm{HbA1c}$ [40]. However, all the included trials used three days of CGMS $[8,14,17,21]$.

In this study, the positive effect of CGMS in the intervention group was not sustained. This nonsustained benefit is evidenced by the fluctuated level of average BSL per month. The average BSL reduced after one month post CGMS but increased back to the baseline level at the second month onward in the intervention group as demonstrated in (figure-III). However, the reduction within both groups was not statistically significant. This finding is consistent with the results of a trial by Ludvigsson et al., who found that the HbA1c level increased back to the baseline after a period of reduction in a trial that involved adolescents and teenagers with poor glycaemic control [17]. This limited effect of CGMS was more prominent in patients with poor and unstable glycaemic control and those with significant day to day glucose variability $[17,21,40]$. The effect of CGMS may also caused 21 by short-lasting motivation and poor adherence to treatment adjustment after a while post-CGMS used $[17,21]$. The persistent small reduction in average monthly BSL in the control group might be due to factors other than the CGMS itself, such as frequent BSL monitoring and better treatment compliance. The effect of CGMS can be prolonged and maintained by repeated use of CGMS [17]. This strategy is supported by a study by Ludvigsson et al., where insulin adjustment based on three days of CGMS every two weeks resulted in a significant reduction in $\mathrm{HbA} 1 \mathrm{c}$ [17].

Despite that we used a longer duration of CGMS (7 days), we could not demonstrate any reduction in $\mathrm{HbA} 1 \mathrm{c}$ in both groups. Other studies that used CGMS for 3 to 5 days, such as a study by Battelino et al., Lagarde et al., and Raviteja et al., showed a reduction in $\mathrm{HbA1C}$ in the CGMS group even though the difference was not significant compared to SMBG $[8,39,41]$. One reason for this observation is that other studies implemented stricter eligibility criteria on top of repeated CGMS applications. These studies also involved children with much better glycaemic control with mean HbA1c of less than $10.0 \%$, lesser hypoglycaemic events at baseline, have a good understanding of diabetes, and known to have good compliance with treatment and follow up $[8,21,39]$. Our respondents consisted of children and adolescents with poor glycemic control and a high frequency of hypoglycaemia. They were mostly from low socioeconomic backgrounds with various levels of understanding and compliance.

In an observational study by $\mathrm{P}$ SchaepelynckBélicar and colleagues, 12 teenagers with poor control T1DM were applied with CGMS for three days. After two months, the $\mathrm{HbA1c}$ reduced significantly [42]. More than $40 \%$ of the respondents were on twice daily insulin injections initially with a mean number of SMBG of less than once per day in this study. Post CGMS, all the respondents were switched to intensive insulin 
regimen with a significantly higher mean number of SMBG per day [42]. The change to more intensive insulin regimes and more frequent SMBG rather than the effect of CGMS might be the reasons for the improvement in $\mathrm{HbA} 1 \mathrm{c}$ [42].

The HE/wk of the intervention group reduced significantly with a concomitant increase in HbA1c post-CGMS used. Similarly, in a study by Yates et al., the authors found that the time in hypoglycaemia increased by $7 \%$ with every $1 \%$ reduction in $\mathrm{HbA1c}[38]$. The inverse relationship between $\mathrm{HbA} 1 \mathrm{c}$ and hypoglycaemia has been demonstrated in a few previous studies $[43,44]$. In a study on T1DM by Tsujino et al. to look at the relationship between $\mathrm{HbA} 1 \mathrm{c}$ and hypoglycaemia, it was found that the duration of both hypoglycaemia and nocturnal hypoglycaemia was inversely proportionate to $\mathrm{HbA} 1 \mathrm{c}$. Every $1.0 \%$ increase in $\mathrm{HbA} 1 \mathrm{c}$ resulted in a reduction in risk of hypoglycaemia and nocturnal hypoglycaemia by $46 \%$ and $41 \%$ each [44]. The relationship between $\mathrm{HbA} 1 \mathrm{C}$ and time in hypoglycaemia was a J-shape relationship where hypoglycaemia was more marked in patients at both extremes of $\mathrm{HbA} 1 \mathrm{c}$ level. Patients with $\mathrm{HbA} 1 \mathrm{c}$ between $8.1 \%$ and $8.6 \%$ had the lowest risk of hypoglycaemia [43]. Ninety-five per cent of our respondents (21 of 22 respondents) had an $\mathrm{HbA} 1 \mathrm{c}$ level of either lower than $8.1 \%$ or higher than $8.6 \%$. Reducing the $\mathrm{HE} / \mathrm{wk}$ increased the $\mathrm{HbA} 1 \mathrm{c}$.

Hypoglycaemia is an important cause of morbidity and contributed to up to $18 \%$ of death in young patients with diabetes [45]. Hypoglycaemia resulted in sudden release of stress hormones such as epinephrine, which triggers the sympathetic nervous system and other pro-inflammatory peptides $[46,47]$. These exaggerated responses trigger inflammation, prothrombotic events, and vasoconstriction that lead to vascular occlusion and ischemic injury[45]. In this study, the use of CGMS significantly reduced the frequency of hypoglycaemic events per week compared to SMBG. Similarly, Schiaffini et al. reported that when CGMS is used by T1DM children twice at six weeks interval, the number of hypoglycaemic events recorded within the 72 hours of CGMS reduced significantly from 3.9 to 2.5 events without significant reduction in $\mathrm{HbA} 1 \mathrm{c}$ [48]. Other studies also found that CGMS able to detect more asymptomatic hypoglycaemia than SMBG, especially with the use of alarm-equipped CGMS devices and real-time CGMS [46,47,49,50].
With the ability to detect more asymptomatic hypoglycaemia, CGMS improved hypoglycaemia awareness and prevented complications attributed to hypoglycaemia [49,51]. CGMS is also safe and readily accepted by children and adolescents with T1DM. No serious adverse effect, such as pain or bleeding reported by the respondents. However, the physical restriction imposed by a CGMS device's attachment may hinder continuous and repetitive use in active school children and adolescents.

\section{Limitation}

There are a few limitations of our study. Although the number of respondents included in this study is sufficient to provide $80 \%$ power to the study to detect a $1 \%$ reduction in $\mathrm{HbA} 1 \mathrm{c}$, the wide $95 \%$ confidence interval increased the probability of type II error. It may lead to failure to detect the true effect of CGMS. The probability of type II error can be reduced by increasing the sample size. However, it is difficult to recruit more respondent who lives farther away from hospital into this trial. Secondly, the high frequency of hypoglycaemic events per week at baseline may reflect tighter control and greater compliance to diet and insulin when CGMS device was used. Longer follow up is required, and the CGMSwearing period can be repeated every month to monitor the frequency of hypoglycaemia and average BSL. However, this strategy will cause difficulty for the respondents to travel more frequently to the hospital for application and removal of CGMS device and thus increase the rate of drop-out and loss to follow up. Nevertheless, the reduction in CGMS group was significantly more than in the SMBG group. Furthermore, this study did not control other non-glycaemic factors that could affect $\mathrm{HbA} 1 \mathrm{c}$, such as iron deficiency and genetic variability $[36,37]$. Future studies that look into the effect of these factors on $\mathrm{HbA} 1 \mathrm{c}$ are required.

The respondents of this study have wide age ranges, i.e. 9 to 21 years old, involved patients on both insulin pump and basal-bolus, and with different glycaemic control (HbA1c ranges between 6.80 and 15.80). Therefore, the findings can be generalised to all paediatric T1DM patients. 


\section{Conclusion}

In conclusion, retrospective use of CGMS in T1DM on intensive insulin therapy demonstrated no significant reduction in $\mathrm{HbA} 1 \mathrm{c}$ but more sensitive than SMBG in detecting hypoglycaemia. If the data derived from CGMS are used to fine-tuning insulin dosage, it could effectively reduce the incidence of hypoglycaemia among the populations with a high rate of asymptomatic hypoglycaemia. The findings of this study need to be interpreted to improve specific clinical outcomes such as glycaemic control and the reduction of hypoglycaemic episodes. However, given some limitation in this study, more study with a larger sample and a longer duration of CGMS is required to confirm the findings.

\section{Acknowledgements}

We want to acknowledge the Malaysia Endocrine and Metabolic Society for the grant provided. We want to thank Dr. Amiro Mohd Radzi, Dr. Nurshafinaz Mohd Fezal, Mrs. Wan Saleha, and Mrs. Nik Salmiah, our research assistants. To Mrs. Nurul Azurah Mohd Roni and Mrs. Noraida Hasssan, the two librarians of University Sains Malaysia have assisted us in referencing steps using endnote and literature searching. Dr. Nor Rosidah and Dr. Siti Azrin for assistance in preparing the research proposal. Mr. Faris, our department officer who has, helps in the purchase of the CGMS device. Lastly, to Miss Zulaikha, HUSM biostatistics student in her assistance on the statistical analysis of data and preparation of the research proposal.

This work was supported by the Malaysia Endocrine and Metabolic Society

\section{References}

[1] Zain, Fuziah Md, Janet Hong Yeow Hua, Zanariah Hussein, Wu Loo Ling, Rahmah Rasat, Chan Siew Pheng, Fatimah Harun, and Geeta Appannah. Annual Report of the Diabetes in Children and Adolescents Registry (2006-2007). Diabetes. 2008.).

[2] Brink SJ. Complications of pediatric and adolescent type 1 diabetes mellitus. Current diabetes reports. 2001; 1 (1): 47-55.
[3] Jamiołkowska M, Jamiołkowska I, Łuczyński W, Tołwińska J, Bossowski A. and Głowińska Olszewska B. Impact of real-time continuous glucose monitoring use on glucose variability and endothelial function in adolescents with type 1 diabetes: New technology-new possibility to decrease cardiovascular risk? JDM. 2016.

[4] Nathan DM \& Group DER. The diabetes control and complications trial/epidemiology of diabetes interventions and complications study at 30 years: Overview. Diabetes care. 2014; 37: 9-16.

[5] Archinkova $M$, Konstantinova $M$, Savova $R$, lotova V, Petrova C, Kaleva N, Koprivarova K, Despotova V, Koleva R, Boyadzhiev V, Mladenov W. Glycemic control among bulgarian children and adolescent with type 1 diabetes - an impact of the social status and the educational level of the parents. B\&BE.2018; 32: 535-541.

[6] Gesuita R, Skrami E, Bonfanti R, Cipriano P, Ferrito $L$, Frongia $P$, lafusco $D$, lannilli $A$, Lombardo F, Mozzillo E, Paleari R. The role of soci-economic and clinical factors on hba1c in children and adolescent with type 1 diabetes: An italian multicentre survey. Pediatr Diabetes. 2016; 18: 241-248.

[7] Noorani M, Ramaiya K \& Manji K. Glycaemic control in type 1 diabetes mellitus among children and adolescents in a resource limited setting in dar es salaam - tanzania. BMC Endocrine Disorders. 2016; 16 (1): 29.

[8] Battelino T, Conget I, Olsen B, SchützFuhrmann I, Hommel E, Hoogma R, Schierloh $\mathrm{U}$, Sulli $\mathrm{N}$, Bolinder J.The use and efficacy of continuous glucose monitoring in type 1 diabetes treated with insulin pump therapy: A randomised controlled trial. Diabetologia 2012; 55: 3155-3162.

[9] Stephen Greene, S. S. G. f. t. C. o. t. Y. D. Factors influencing glycemic control in young people with type 1 diabetes in scotland: A population-based study (diabaud2). Diabetes Care. 2001; 24: 239-244.

[10] Melo KF, Bahia LR, Pasinato B, Porfirio GJ, Martimbianco AL, Riera $R$, Calliari $L E$, Minicucci WJ, Turatti LA, Pedrosa HC, Schaan $B D$. Short-acting insulin analogues versus regular human insulin on postprandial glucose and hypoglycemia in type 1 diabetes mellitus: A systematic review and meta analysis. Diabetology and Metabolic 
Syndrome. 2019; 11(1): 1-13. doi:10.1186/s13098-018-0397-3.

[11] Ziegler R, Heidtmann B, Hilgard D, Hofer S, Rosenbauer J, Holl R, DPV-Wiss-Initiative. Frequency of smbg correlates with hba1c and acute complications in children and adolescents with type 1 diabetes. Pediatric diabetes. 2011; 12:11-17.

[12] Özyazıcıoğlu N, Avdal EÜ, Sağlam H. A determination of the quality of life of children and adolescent with type 1 diabetes and their parents. IJNSS. 2017; 4: 94-98 doi:10.1016/j.ijnss.2017.01.008.

[13] Borus JS and Laffel L. Adherence challenges in the management of type 1 diabetes in adolescents: Prevention and intervention. CURR OPIN PEDIATR. 2010; 22: 405 doi:10.1097/MOP.0b013e32833a46a7.

[14] Hermanides J, Nørgaard K, Bruttomesso D, Mathieu C, Frid A, Dayan CM, et al. Sensoraugmented pump therapy lowers hba1c in suboptimally controlled type 1 diabetes; a randomized controlled trial. Diabetic Medicine. 2011; 28: 1158-1167.

[15] Rodbard D. Continuous glucose monitoring: A review of successes, challenges, and opportunities. Diabetes Technol Ther. 2016; 18: S3-S13.

[16] Salardi S, Zucchini S, Santoni R, Ragni L, Gualandi S, Cicognani A, Cacciari E. The glucose area under the profiles obtained with continuous glucose monitoring system relationships with hbalc in pediatric type 1 diabetic patients. Diabetes Care. 2002; 25, 1840-1844.

[17] Ludvigsson J \& Hanas R. Continuous subcutaneous glucose monitoring improved metabolic control in pediatric patients with type 1 diabetes: A controlled crossover study. Pediatrics. 2003; 111: 933-938.

[18] Reilly JJ and Wilson D. Childhood obesity. BMJ. 2006; 333: 1207-1210.

[19] Ahmad Haris Mohd Zukki, JTRYa. \& Rahuman MRH. BNM Quarterly Bulletin. Department of Statistics Malaysia, Bank Negara Malaysia. 2018; Second Quarter 2018: 19 - 24

[20] Geoffrey C. Urbaniak SP. Research randomizer (version 4.0) (computer software), http://www.randomizer.org/.

(2018). Accessed on $1^{\text {st }}$ February 2018.

[21] Deiss D, Hartmann R, Schmidt J and Kordonouri $O$. Results of a randomised controlled cross-over trial on the effect of continuous subcutaneous glucose monitoring (cgms) on glycaemic control in children and adolescents with type 1 diabetes. Exp. Clin. Endocrinol. Diabetes. 2006; 114: 63-67.

[22] Weykamp C. Hba1c: A review of analytical and clinical aspects. APALM. 2013; 33: 393.

[23] Janet Hong YH, CYK, Hassan N, Md Zain Fuziah, Hussain S, Chow YN, Jalaludin $M$. Yazid. Management of Type 1 Diabetes Mellitus in Children \& Adolescents. Malaysia Health Technology Assessment Section (MaHTAS). 2015; Putrajaya, Malaysia.

[24] DiMeglio LA, Acerini CL, Codner E, Craig ME, Hofer SE, Pillay K, Maahs DM. Ispad clinical practice consensus guidelines 2018: Glycemic control targets and glucose monitoring for children, adolescents, and young adults with diabetes. 2018.

[25] Zhou J, Mo Y, Li H, Ran X, Yang W, Li Q, Peng Y, Li Y, Gao X, Luan X, Wang W. Relationship between hba1c and continuous glucose monitoring in chinese population: A multicenter study. PLOS ONE. 2013; 8: e83827. doi:10.1371/journal.pone.0083827.

[26] Gerstl EM, Rabl W, Rosenbauer J, Gröbe H, Hofer SE, Krause U, Holl RW. Metabolic control as reflectet by hba1c in children, adolescents and young adults with type- 1 diabetes mellitus: Combined longitudinal analysis including 27,035 patients from 207 centers in germany and austria during the last decade. EJPE. 2008; 167: 447-453.

[27] Foster NC, Beck RW, Miller KM, Clements MA, Rickels MR, DiMeglio LA, et al. State of type 1 diabetes management and outcomes from the t1d exchange in 2016-2018. Diabetes Technol Ther. 2019; 21: 66-72. doi:10.1089/dia.2018.0384.

[28] Danne T, Phillip M, Buckingham BA, JaroszChobot P, Saboo B, Urakami T, Battelino T, Hanas R, Codner E. ISPAD Clinical Practice Consensus Guidelines 2018: Insulin treatment in children and adolescents with diabetes. Pediatric diabetes. 2018;19:115-35.

[29] Strich D, Balagour L, Shenker J and Gillis D. Lower basal insulin dose is associated with better control in type 1 diabetes. J Pediatr. 2017; 182: 133-136.

[30] Matejko B, Kukułka A, Kieć-Wilk B, Stąpór A, Klupa T, Malecki MT. Basal insulin dose in adults with type 1 diabetes mellitus on insulin pumps in real-life clinical practice: $A$ 
single-center experience. Advances in medicine. 2018; 2018.

[31] Strich D, Teomim R and Gillis D. The basal insulin dose; a lesson from prolonged fasting in young individuals with type 1 diabetes. Pediatr Diabetes. 2015; 16: 629-633.

[32] Hassan K, Loar R, Anderson BJ and Heptulla RA. The role of socioeconomic status, depression, quality of life, and glycemic control in type 1 diabetes mellitus. J Pediatr. 2006; 149: 526-531.

[33] Al-Odayani, Abdulrahman Nasser, Omar Zayyan Alsharqi, Abdulrahman Ala'Eddin Mohammad Khalaf Ahmad, and Khazim AlAsmari et al.Children's glycemic control: Mother's knowledge and socioeconomic status. GJHS. 2013; 5: 214.

[34] Carter PJ, Cutfield WS, Hofman PL, Gunn AJ, Wilson DA, Reed PW, Jefferies C. Ethnicity and social deprivation independently influence metabolic control in children with type 1 diabetes. Diabetologia. 2008; 51: 1835. doi:10.1007/s00125-008-1106-9.

[35] English E, Idris I, Smith G, Dhatariya K, Kilpatrick ES, John WG. The effect of anaemia and abnormalities of erythrocyte indices on hba 1c analysis: A systematic review. Diabetologia. 2015; 58: 1409-1421.

[36] Christy AL, Manjrekar PA, Babu RP and Hegde A. Influence of iron deficiency anemia on hemoglobin a1c levels in diabetic individuals with controlled plasma glucose levels. IBJ. 2014; 18: 88.

[37] Cavagnolli G, Pimentel AL, Freitas PAC, Gross $\mathrm{JL}$ and Camargo JL. Effect of ethnicity on hba1c levels in individuals without diabetes: Systematic review and meta-analysis. PLoS One. 2017; 12: e0171315.

[38] Yates K, Hasnat Milton A, Dear K and Ambler G. Continuous glucose monitoring-guided insulin adjustment in children and adolescents on near-physiological insulin regimens: A randomized controlled trial. Diabetes Care. 2006; 29: 1512-1517. doi:10.2337/dc05-2315.

[39] Raviteja K, Kumar R, Dayal D and Sachdeva N. Clinical efficacy of professional continuous glucose monitoring in improving glycemic control among children with type 1 diabetes mellitus: An open-label randomized control trial. Scientific reports. 2019; 9: 6120.

[40] Langendam M, Luijf YM, Hooft L, DeVries JH, Mudde AH, Scholten RJ. Continuous glucose monitoring systems for type 1 diabetes mellitus. Cochrane Database Syst. Rev. 2012; doi:10.1002/14651858.CD008101.pub2.

[41] Lagarde $W H$, Barrows FP, Davenport ML, Kang M, Guess HA, Calikoglu AS. Continuous subcutaneous glucose monitoring in children with type 1 diabetes mellitus: A single-blind, randomized, controlled trial. Pediatr Diabetes. 2006; 7: 159-164.

[42] Schaepelynck-Belicar P, Vague P, Simonin G and Lassmann-Vague V. Improved metabolic control in diabetic adolescents using the continuous glucose monitoring system (cgms). DMJ. 2003; 29: 608-612 doi:10.1016/s1262-3636(07)70076-9.

[43] Gimenez M, Tannen AJ, Reddy M, Moscardo V, Conget I, Oliver N. Revisiting the relationships between measures of glycemic control and hypoglycemia in continuous glucose monitoring data sets. Diabetes Care. 2018; 41: 326-332.

[44] Tsujino D, Nishimura R, Onda $Y$, Seo C, Ando K, Morimoto A, Utsunomiya K. The relationship between $\mathrm{HbA} 1 \mathrm{c}$ values and the occurrence of hypoglycemia as assessed by continuous glucose monitoring in patients with type 1 diabetes. Diabetology \& metabolic syndrome. 2016 Dec;8(1):1-7.

[45] Graveling AJ and Frier BM. Does hypoglycaemia cause cardiovascular events? Br. j. diabetes vasc. dis.2010; 10: 5-13.

[46] Novodvorsky P, Bernjak A, Chow E, lqbal A, Sellors L, Williams S, Fawdry RA, Parekh B, Jacques RM, Marques JL, Sheridan PJ. Diurnal differences in risk of cardiac arrhythmias during spontaneous hypoglycemia in young people with type 1 diabetes. Diabetes care. 2017;40(5):655-62.

[47] Biester T, Kordonouri O, Holder M, Remus K, Kieninger-Baum D, Wadien T, Danne T. "Let the algorithm do the work": reduction of hypoglycemia using sensor-augmented pump therapy with predictive insulin suspension (SmartGuard) in pediatric type 1 diabetes patients. Diabetes technology \& therapeutics. 2017;19(3):173-82.

[48] Schiaffini R, Ciampalini $P$, Fierabracci A, Spera S, Borrelli P, Bottazzo GF, Crino A. The continuous glucose monitoring system (cgms) in type 1 diabetic children is the way to reduce hypoglycemic risk. Diabetes Metab. Res. Rev.. 2002; 18: 324-329. doi:10.1002/dmrr.309. 
[49] Wolpert HA. Use of continuous glucose monitoring in the detection and prevention of hypoglycemia. JDST. 2007; 1: 146-150. doi:10.1177/193229680700100126.

[50] Battelino T, Phillip M, Bratina N, Nimri R, Oskarsson P, Bolinder J. Effect of continuous glucose monitoring on hypoglycemia in type 1 diabetes. Diabetes care. 2011; 34: 795-800.

[51] Hirsch IB, Battelino T and Peters AL. Role of continuous glucose monitoring in diabetes treatment. American Diabetes Association. 2018. 


\section{Supplementary}

\section{Data Collection Form}

Title:

Continuous Subcutaneous Glucose Monitoring Vs. Self-Monitoring Blood Glucose InPaediatric Patients With Type 1 Diabetes: A Randomised Controlled Trial

\begin{tabular}{|c|c|c|}
\hline Subject No & $:$ & \\
\hline Gender & : $\square$ Male & $\square$ Female \\
\hline Age & :___ years & \\
\hline Race & $:$ & \\
\hline Height & $: \ldots \mathrm{cm}$ & \\
\hline Weight & $: \ldots$ kg & \\
\hline BMI & $: \ldots \mathrm{kg} / \mathrm{m}^{2}$ & \\
\hline Waist Circ & $: \ldots \mathrm{cm}$ & \\
\hline $\mathrm{BP}$ & $: \mathrm{mmHg}$ & \\
\hline Tanner Staging & : Pre-puberty & $\square$ Post-puberty \\
\hline Duration of DM & $:$ ___ months & \\
\hline Total insulin & : __ iu/kg/day & \\
\hline
\end{tabular}

Average number of hypoglycemia/month:

Insulin Delivery : $\square$ Multiple injections $\quad \square$ Insulin Pump

Baseline $\mathrm{HbA} 1 \mathrm{c}$ : $\%$

Other co-morbid :

\begin{tabular}{|l|l|l|l|l|}
\hline & $1^{\text {st }}$ visit & $2^{\text {nd }}$ visit & $3^{\text {rd }}$ visit & $4^{\text {th }}$ visit \\
\hline Date & & & & \\
\hline Highest CBS & & & & \\
\hline Lowest CBS & & & & \\
\hline $\begin{array}{l}\text { Mean CBS/week } \\
\text { (mmol) }\end{array}$ & & & & \\
\hline $\begin{array}{l}\text { No of } \\
\text { hypoglycemic } \\
\text { episode/ week }\end{array}$ & & & & \\
\hline HbA1c & & & & \\
\hline
\end{tabular}


Table 1. Comparison of mean and 95\% confidence interval of average BSL per month between CGMS and SMBG groups

\begin{tabular}{|l|l|l|l|l|}
\hline \multirow{2}{*}{ month } & \multicolumn{2}{|l|}{ Adjusted mean $(95 \% \mathrm{Cl})$} & \multirow{2}{*}{ F statistics $^{\mathrm{a}}(\mathrm{df})$} & \multirow{2}{*}{ P value $^{\mathrm{a}}$} \\
\cline { 2 - 3 } & Intervention & Control & & \\
\hline M0 & $7.90(6.60,9.28)$ & $8.38(6.37,10.39)$ & \\
\hline M1 & $7.65(6.85,8.44)$ & $8.56(6.47,10.66)$ & \multirow{2}{*}{$0.195(1)$} & \multirow{2}{*}{0.663} \\
\hline M2 & $7.91(6.87,8.95)$ & $8.28(6.07,10.49)$ & & \\
\hline M3 & $7.88(6.87,8.89)$ & $7.85(5.80,9.90)$ & & \\
\hline
\end{tabular}

${ }^{\mathrm{a}}$ Repeated measure ANOVA

There is no significant mean difference of average BSL between intervention and control groups; $F(1,20)=$ $0.195, p=0.663$

Table 2. The mean difference of average BSL per month within each group

\begin{tabular}{|l|l|l|l|l|}
\hline \multirow{2}{*}{ Comparison } & \multicolumn{2}{|l|}{ Intervention } & \multicolumn{2}{l|}{ Control } \\
\cline { 2 - 5 } & Mean difference $(95 \% \mathrm{Cl})$ & P value & Mean difference $(95 \% \mathrm{Cl})$ & P value $^{\mathrm{a}}$ \\
\hline M0 - M1 & $0.29(-1.05,1.64)$ & 0.637 & $-0.19(-1.85,1.48)$ & 0.808 \\
\hline M0 - M2 & $0.03(-1.42,1.47)$ & 0.966 & $0.10(-1.62,1.83)$ & 0.896 \\
\hline M0 - M3 & $0.06(-1.37,1.49)$ & 0.928 & $0.53(-1.11,2.17)$ & 0.487 \\
\hline M1 - M2 & $-0.27(-0.79,0.26)$ & 0.283 & $0.29(-0.02,0.60)$ & 0.064 \\
\hline M1 - M3 & $-0.24(-0.79,0.32)$ & 0.367 & $0.72(0.33,1.10)$ & $0.002^{\mathrm{b}}$ \\
\hline M2 - M3 & $0.03(-0.28,0.35)$ & 0.831 & $0.43(0.08,0.78)$ & $0.022^{\mathrm{b}}$ \\
\hline
\end{tabular}

${ }^{\text {aPaired } t} \mathrm{t}$ test. ${ }^{\mathrm{b} S}$ Significant different after Bonferroni correction

There is no significant difference for all monthly mean BSL with time for intervention group. But control group, significant difference was observed between month 1 - month 3 and month 2 - month 3 . $F(3,60)$ $=0.263, p=0.655$ 
Table 3. Comparison of mean and 95\% confidence interval of mean HE/wk per month between CGMS and SMBG groups

\begin{tabular}{|l|l|l|l|l|}
\hline \multirow{2}{*}{ Month } & \multicolumn{2}{|l|}{ Adjusted mean $(95 \% \mathrm{Cl})$} & \multirow{2}{*}{ F statistics $^{\mathrm{a}}(\mathrm{df})$} & \multirow{2}{*}{ P value $^{\mathrm{a}}$} \\
\cline { 2 - 3 } & Intervention & Control & & \\
\hline M0 & $4.64(1.57,7.70)$ & $1.64(0.39,2.89)$ & & \\
\hline M1 & $1.23(0.35,2.11)$ & $0.66(0.10,1.23)$ & \multirow{2}{*}{$0.082(1)$} & \\
\hline M2 & $1.32(0.33,2.31)$ & $0.41(0.02,0.80)$ & & \\
\hline M3 & $1.05(0.04,2.05)$ & $0.46(0.02,0.90)$ & & \\
\hline
\end{tabular}

${ }^{\text {a }}$ Repeated measure ANOVA

There is significant mean different of mean HE/wk between intervention and control group; $F(1,20)=4.982$, $\mathrm{p}=0.037$

Table 4. The mean difference of mean HE/wk per month within each group

\begin{tabular}{|c|c|c|c|c|}
\hline \multirow{2}{*}{ Comparison } & \multicolumn{2}{|l|}{ Intervention } & \multicolumn{2}{|l|}{ Control } \\
\hline & Mean difference $(95 \% \mathrm{Cl})$ & $P_{\text {value }}{ }^{a}$ & Mean difference $(95 \% \mathrm{Cl})$ & Pvalue \\
\hline M0 - M1 & $3.409(0.398,6.420)$ & $0.030^{b}$ & $0.973(0.126,1.819)$ & $0.028^{b}$ \\
\hline MO - M2 & $3.318(0.576,6.061)$ & $0.022^{b}$ & $1.227(0.172,2.283)$ & $0.027^{b}$ \\
\hline MO - M3 & $3.591(0.276,6.905)$ & $0.036^{b}$ & $1.182(0.075,2.289)$ & $0.039^{b}$ \\
\hline M1 - M2 & $-0.091(-0.607,0.426)$ & 0.703 & $0.255(-0.055,0.564)$ & 0.097 \\
\hline M1 - M3 & $0.182(-0.344,0.708)$ & 0.459 & $0.209(-0.237,0.655)$ & 0.321 \\
\hline M2 - M3 & $0.272(-0.405,0.951)$ & 0.391 & $-0.045(-0.325,0.234)$ & 0.724 \\
\hline
\end{tabular}

apaired t test. ${ }^{b}$ Significant different after Bonferroni correction

There are significant differences for mean hypoglycaemia episodes per week with time for both CGMS and SMBG group observed between M0 - M1, M0 - M2 and M0 - M3. F (3,60) $=9.752, p=0.004$ 